Supporting Information

\title{
Tailoring Azlactone-Based Block Copolymers for Stimuli-Responsive Disassembly of Nanocarriers
}

\begin{abstract}
Liangying Jia ${ }^{\mathrm{a}}$, S. Michael Kilbey II*,b,c and Xu Wang*,a,d
aNational Engineering Research Center for Colloidal Materials, School of Chemistry and Chemical Engineering, Shandong University, Jinan, Shandong 250100, China.

bDepartment of Chemistry, University of Tennessee, Knoxville, TN 37996, USA.

'Department of Chemical and Biomolecular Engineering, University of Tennessee, Knoxville, TN 37996, USA.

dShenzhen Research Institute of Shandong University, Shenzhen, Guangdong 518057, China.

*Emails: wangxu@sdu.edu.cn (X.W.); mkilbey@utk.edu (S.M.K.II).
\end{abstract}

\begin{tabular}{|c|c|}
\hline Number of pages: & 5 \\
\hline Number of figures: & 4 \\
\hline Number of schemes: & 1 \\
\hline
\end{tabular}

This file includes:

1. ${ }^{1} \mathrm{H}$ NMR spectra of the block copolymers: (Figures S1-S2).

2. FTIR spectra of PVDMA before and after immersing in water for 5 days: (Figure S3).

3. AFM height images and TEM images of $\mathrm{PEG}_{113}-b-\mathrm{PVDMA}_{183}-f-\mathrm{AzO}_{62} \quad \mathrm{BCPs}$ before and after the addition of $\beta-\mathrm{CD}$ : (Figure S4).

4. Idealized depiction of the interaction between $\beta-C D$ and Azo-functionalized PEG- $b$-PVDMA BCPs at low or high functionalization ratios in aqueous solution: (Scheme S1). 


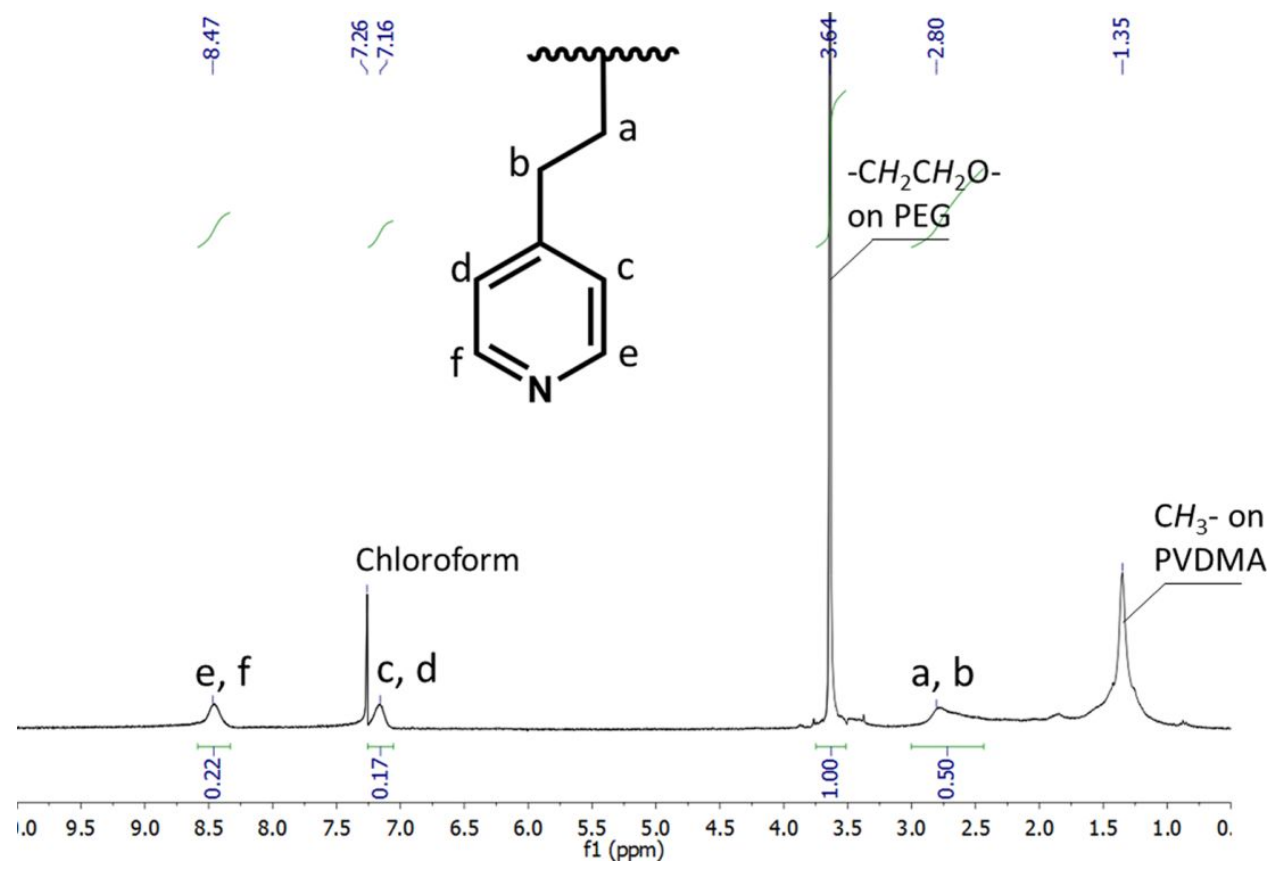

Figure S1. ${ }^{1} \mathrm{H}$ NMR spectrum of $\mathrm{PEG}_{113}-b-\mathrm{PVDMA}_{183}-f-\mathrm{Pyr}_{50}$ in $\mathrm{CDCl}_{3}$. The number of $\mathrm{Pyr}$ groups in the polymer is calculated based on the relative integrated peaks areas of the peaks at 3.64 ppm (for PEG) and at 8.47 ppm (for Pyr). 


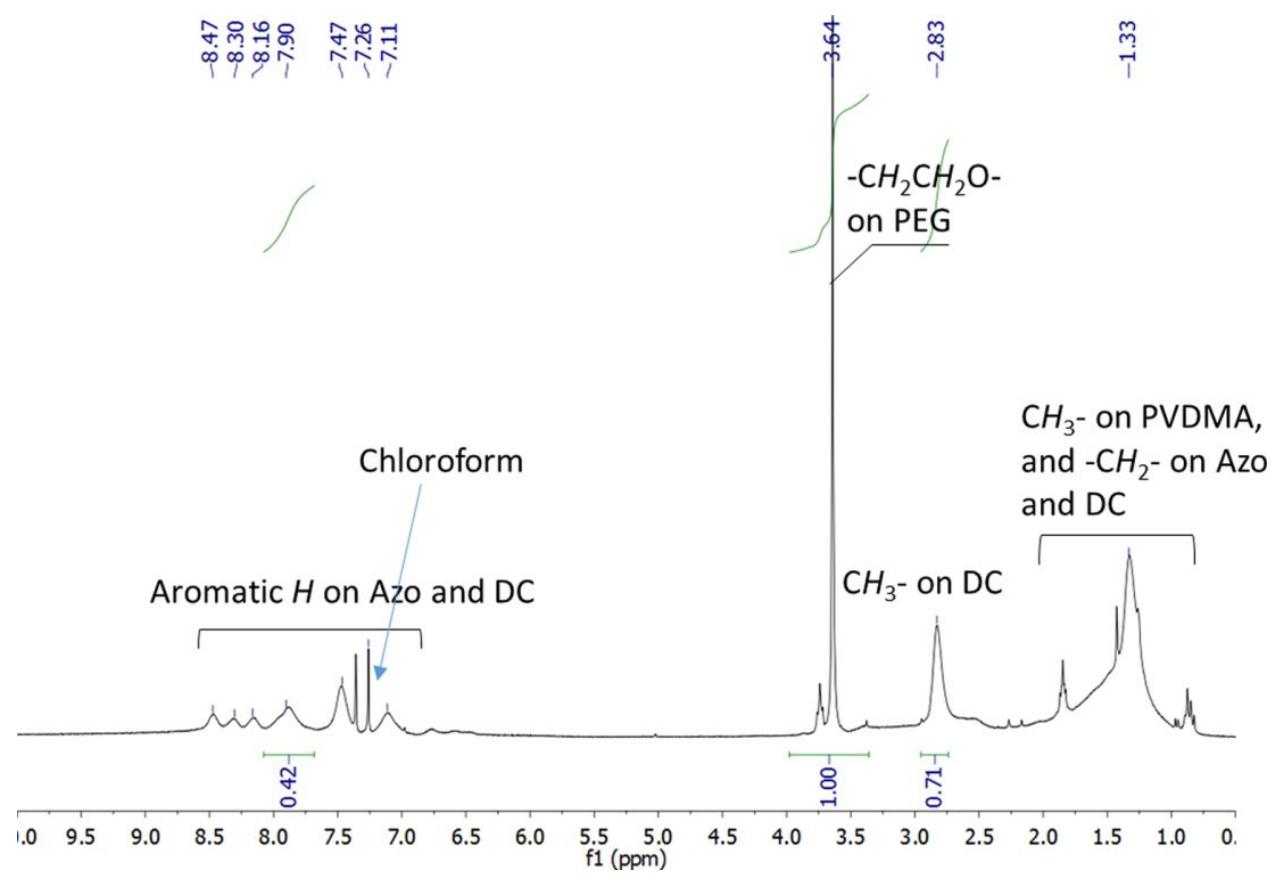

Figure S2. ${ }^{1} \mathrm{H}$ NMR spectrum of $\mathrm{PEG}_{113}-b-\mathrm{PVDMA}_{183}-f-\mathrm{AzO}_{31}-\mathrm{DC}_{46}$ in $\mathrm{CDCl}_{3}$. The number of DC groups in the polymer is calculated based on the relative peak area of the peaks at $3.64 \mathrm{ppm}$ (for PEG) and 2.83 ppm (for DC). 


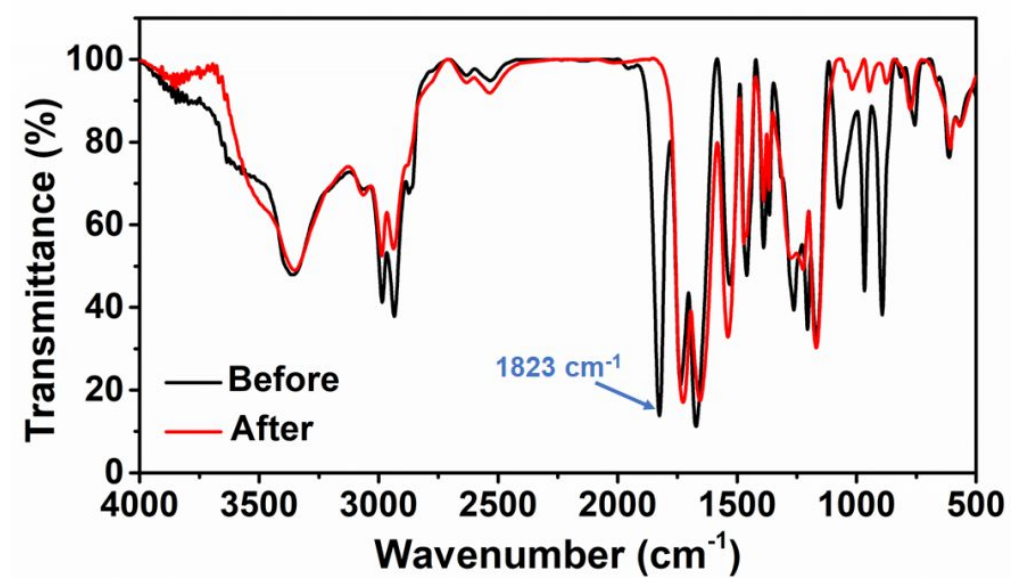

Figure S3. FTIR spectra of PVDMA before (black curve) and after (red curve) immersing in water for 5 days. The disappearance of the carbonyl of the azlactone ring (at $1823 \mathrm{~cm}^{-1}$ ) suggests that the weak nucleophile water causes ring opening of azlactone rings along the chain.

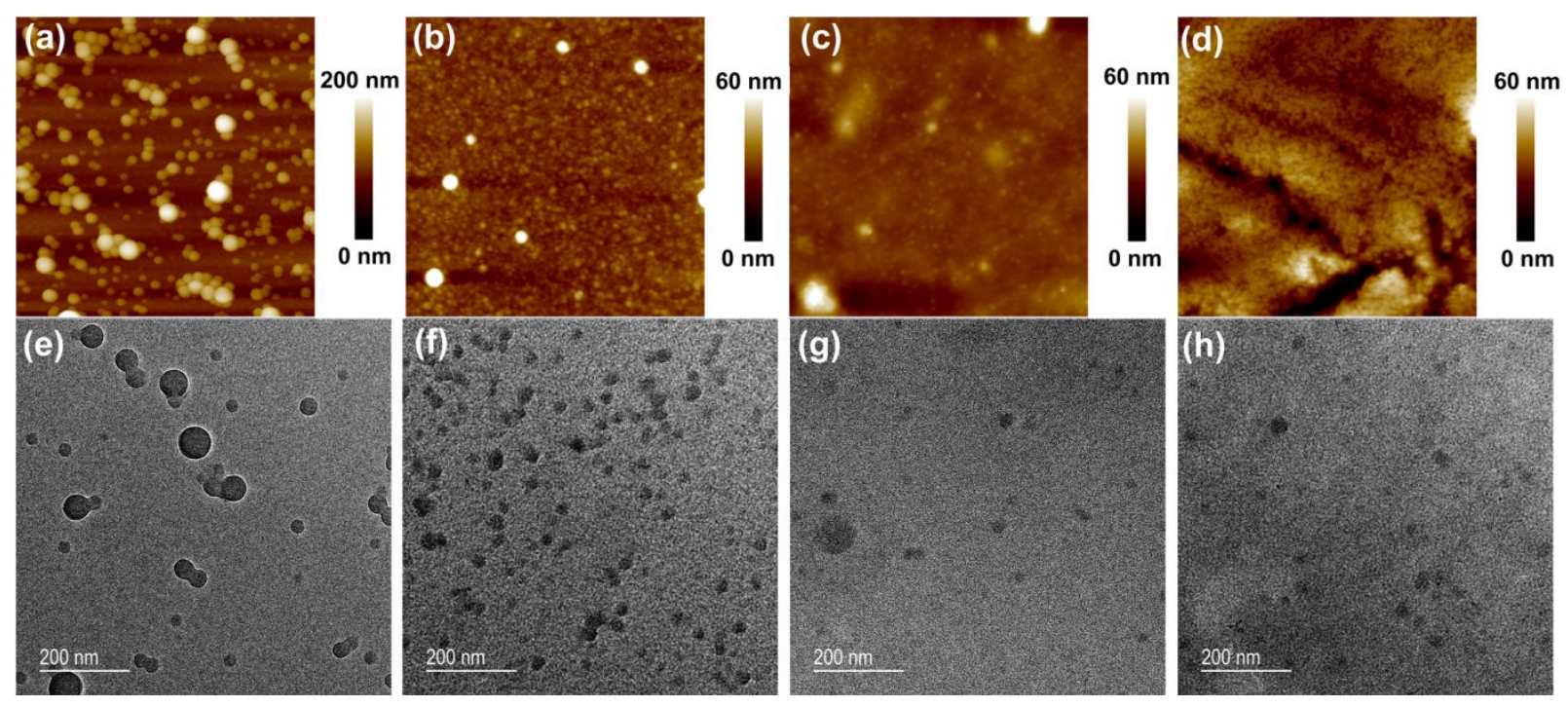

Figure S4. AFM height images $(2 \mu \mathrm{m} \times 2 \mu \mathrm{m})(\mathrm{a}-\mathrm{d})$ and TEM images (e-h) of $\mathrm{PEG}_{113}-b-\mathrm{PVDMA}_{183}-f-\mathrm{Azo}_{62}$ BCPs at day $0(\mathrm{a}, \mathrm{e})$ and at day 5 (b-d, f-h) before $(\mathrm{a}, \mathrm{b}, \mathrm{e}, \mathrm{f})$ and after $(\mathrm{c}, \mathrm{d}, \mathrm{g}, \mathrm{h})$ the addition of $\beta$-CD at molar ratios of $\beta$-CD:Azo $=1: 1(\mathrm{c}, \mathrm{g})$ and 5:1 (d, h). 


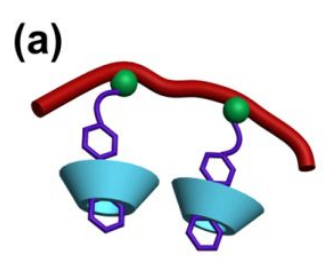

Low grafting ratio

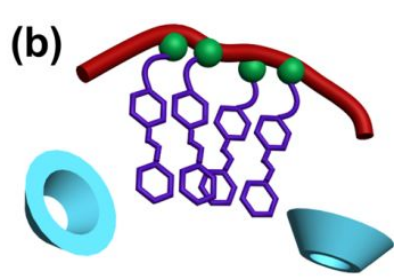

High grafting ratio

Scheme S1. Idealized depiction of the interaction between $\beta-C D$ and Azo-functionalized PEG- $b$-PVDMA BCPs at low (a) or high (b) functionalization ratios in aqueous solution. The steric hinderance of azobenzene groups at high functionalization and their $\pi$-stacking interactions, which for simplification is drawn on one side of the polymer chains, prevent "threading" of $\beta-\mathrm{CD}$ on Azo groups. 